\title{
Global Expression Patterns of Three Festuca Species Exposed to Different Doses of Glyphosate Using the Affymetrix GeneChip Wheat Genome Array
}

\author{
Ozge Cebeci and Hikmet Budak \\ Biological Sciences \& Bioengineering Program, Faculty of Engineering and Natural Sciences, Sabanci University, \\ Orhanli, Tuzla, Istanbul 34956, Turkey \\ Correspondence should be addressed to Hikmet Budak, budak@sabanciuniv.edu
}

Received 15 May 2009; Accepted 4 November 2009

Recommended by Eivind Hovig

Glyphosate has been shown to act as an inhibitor of an aromatic amino acid biosynthetic pathway, while other pathways that may be affected by glyphosate are not known. Cross species hybridizations can provide a tool for elucidating biological pathways conserved among organisms. Comparative genome analyses have indicated a high level of colinearity among grass species and Festuca, on which we focus here, and showed rearrangements common to the Pooideae family. Based on sequence conservation among grass species, we selected the Affymetrix GeneChip Wheat Genome Array as a tool for the analysis of expression profiles of three Festuca (fescue) species with distinctly different tolerances to varying levels of glyphosate. Differences in transcript expression were recorded upon foliar glyphosate application at $1.58 \mathrm{mM}$ and $6.32 \mathrm{mM}$, representing $5 \%$ and $20 \%$, respectively, of the recommended rate. Differences highlighted categories of general metabolic processes, such as photosynthesis, protein synthesis, stress responses, and a larger number of transcripts responded to $20 \%$ glyphosate application. Differential expression of genes encoding proteins involved in the shikimic acid pathway could not be identified by cross hybridization. Microarray data were confirmed by RT-PCR and qRT-PCR analyses. This is the first report to analyze the potential of cross species hybridization in Fescue species and the data and analyses will help extend our knowledge on the cellular processes affected by glyphosate.

Copyright ( 2009 O. Cebeci and H. Budak. This is an open access article distributed under the Creative Commons Attribution License, which permits unrestricted use, distribution, and reproduction in any medium, provided the original work is properly cited.

\section{Introduction}

Glyphosate (N-phosphonomethylglycine) is a broad spectrum herbicide that affects plants systemically after application to the leaf surface. It is phytotoxic and prevents further growth by blocking aromatic amino acid production, leading to the arrest of protein synthesis and secondary compound formation. It specifically inhibits 5-enolpyruvylshikimate-3phosphate synthase (EPSPS), a nuclear encoded chloroplastlocalized enzyme in the shikimic acid pathway of plants and microorganisms [1].

Although it is relatively inexpensive and less toxic to nontarget organisms, glyphosate has not been extensively used in turfgrass weed management programs due to its possible adverse effects on turfgrass growth [2]. Until now, glyphosate usage has been limited to spot treatments. However, in the presence of natural glyphosate-tolerant turfgrass species, such as cool-season perennial turfgrass, there is an increased reliance on the usage of glyphosate for weed control [2]. The development of cultivars with greater tolerance to glyphosate is considered to be a good alternative for weed control using this environmentally friendly herbicide in lawns, golf courses, and other turf areas. Additionally, determining the effective glyphosate rate that can be used directly on turfgrass fields to control weeds is essential for extensive usage of this herbicide. Evolution of resistance to other herbicides, with different modes of action, increased reliance on the herbicide glyphosate for weed control [3]. A better understanding of its action on turfgrass species is essential for the development of future management strategies both to slow down the evolution of resistance and to control existing populations [4]. 
Microarray hybridization is a valuable tool to analyze whole genome expression changes upon any treatment. However, a commercial array platform is not available for turfgrass species. Cross-Species Hybridization $(\mathrm{CSH})$ is a new and useful tool to perform a large-scale functional profiling without an available genome sequence to identify genes that are conserved among species throughout evolution. In addition, it offers an important tool for identifying molecular mechanisms and pathways conserved among species [57]. These studies included CSH analysis of highly diverged species, Caenorhabditis elegans and Drosophila melanogaster [5], and of more related organisms, Candida albicans and Saccharomyces cerevisiae [7]. In a recent study [8], mechanisms controlling embryonic stem cell (ESC) pluripotency were investigated by comparing gene expression patterns of human and mouse ESC orthologous genes. Another recent study reported that usage of a multispecies cDNA array identified conserved genes expressed in oocytes. Gene sequences from three organisms, bovine, mouse, and Xenopus laevis, diverged in their evolutionary position, have been utilized to design a multispecies cDNA array for the identification of conserved sequences playing roles in molecular mechanisms or pathways common to all species [9]. In both studies evolutionarily distant species were selected to identify common mechanisms and pathways. Additionally, a comparison of results obtained by CSH using species specific hybridization (SSH) proved that biological processes analyzed by $\mathrm{CSH}$ closely reflected the analysis found by SSH [10].

The Affymetrix GeneChip Wheat Genome Array was selected to identify global gene expression changes in three selected fescues. The rationale for selecting the wheat genome array for the $\mathrm{CSH}$ experiment was based on the close relatedness of perennial ryegrass, which is relatively similar to fescues, to the Triticeae [11]. In the same study, the existence of synteny and colinearity among the genetic maps of ryegrass and Triticeae cereals has been postulated. Triticeae, ryegrass, and fescues reside in the same subfamily, Pooideae of the Poaceae family [12]. High level of similarity in terms of gene order among these families makes it feasible to consider $\mathrm{CSH}$ to reveal the cross-species conservation of biological processes and their genetic control mechanisms. Festuca species were selected for their differential glyphosate tolerance based on dry matter production, chlorophyll content, and shoot concentration of shikimic acid [4]. Based on these morphological and physiological data, selected genotypes were used to analyze and understand global expression changes upon glyphosate treatments. Large-scale functional profiling of Festuca species with differential tolerance to glyphosate treatment will be a beneficial resource for future investigations concerning biochemical effects of glyphosate on turfgrasses.

\section{Materials and Methods}

2.1. Plant Materials. Seeds of three different turfgrass species, Ambrose (Festuca rubra subsp. falax), Cindy Lou (Festuca rubra subsp. littoralis), and Discovery (Festuca brevipila) were directly planted on soil and grown under controlled conditions in the greenhouse with daytime and nighttime temperatures of $25^{\circ} \mathrm{C}$ and $20^{\circ} \mathrm{C}$, respectively. Glyphosate [RoundUp Ultra; acid equivalent (a.e.): $356 \mathrm{~g} \mathrm{~L}^{-1} \mathrm{~N}$-[phosphonomethyl]glycine, Monsanto Co.] treatment was performed four weeks after sowing by spraying a total volume of $100 \mathrm{~mL}$ of either $5 \%$ or $20 \%$ solution (1.58 $\mathrm{mM}$ and $6.32 \mathrm{mM}$, resp.) directly on the leaves under open air conditions. Plants at the three-leaf growth stage were sprayed with freshly prepared glyphosate solution until all leaves were fully wet (about $10 \mathrm{~mL}$ ) but without runoff. Control plants were sprayed with distilled water. Leaf samples were collected 5 days after treatment.

2.2. RNA Isolation. Total RNA isolations were carried out by Trizol reagent (Invitrogen) according to the manufacturer's instructions. Three separate RNA isolations were performed for each glyphosate dose of each species. RNA concentrations were determined spectrophotometrically and RNA qualities were checked by denaturing gel before the microarray analysis.

2.3. Gene Chip Analysis. All hybridizations were performed as biological triplicates of control and glyphosate treated samples (RNA isolation and cRNA labeling were done separately for each hybridization) of three Festuca genotypes and two glyphosate doses according to the manufacturer's instructions. Cell intensity files were analyzed using Partek Genomics Suite version 6.3 Beta (Partek incorporated) with robust multichip average normalization [13]. The data quality was confirmed by PCA (Principal Component Analysis) and box-whisker plots. Analysis of variance (ANOVA) was used to further analyze the log-transformed expression with the defined threshold expression values of $P<0.1$ and $\mathrm{DE}<-2$ or $\mathrm{DE}>2$. Raw data is deposited in to the ArrayExpress database (http://www.ebi.ac.uk/). Cluster and Treeview programs were used for identification of differentially expressed probes $[14,15]$.

2.4. RT-PCR Analysis. RT-PCR analysis was performed as outlined by Cebeci et al. [16] with minor modifications. cDNAs were quantified spectrophotometrically and diluted to $400 \mathrm{ng} \mu \mathrm{L}^{-1}$. One $\mu \mathrm{L}$ of this cDNA was amplified with $0.5 \mu \mathrm{M}$ of gene specific primers and 18S rRNA primers in a total of $20 \mu \mathrm{L}$ volume. The primer pair selected for RT validation was specific to alternative oxidase because it was found to be up-regulated in all three species. Primers for Germin-Like protein 1 precursor, Chlorophyll a/b-binding protein WCAB precursor, and Thylakoid membrane phosphoprotein $14 \mathrm{kDa}$, chloroplast precursor were also designed for RT validation. Sequences of the primers designed to amplify (1) a region of $196 \mathrm{bp}$ are as follows: TA.233.1.S1_AT (Alternative oxidize), forward: CGTCCACTCCTACACCGAGT/reverse: TGGTAGTACACGTCCGATGC; (2) a region of 156 bp, TA.28351.1.S1_AT (Germin-like protein 1 precursor) forward: GGCCTGCAGATCACTGACTA, reverse: CACGACGAACTTTGCTGAGA; (3) a region of $150 \mathrm{bp}$, TA.30702.1.S1_X_AT (Chlorophyll a/b-binding protein $\mathrm{WCAB}$ precursor) forward: GGAGATCAAGAACGGTCGTC, reverse: ACGAAGTTAGTGGCGAATGC. (4) a region of $207 \mathrm{bp}$, TA.636.1.S1_S_AT 


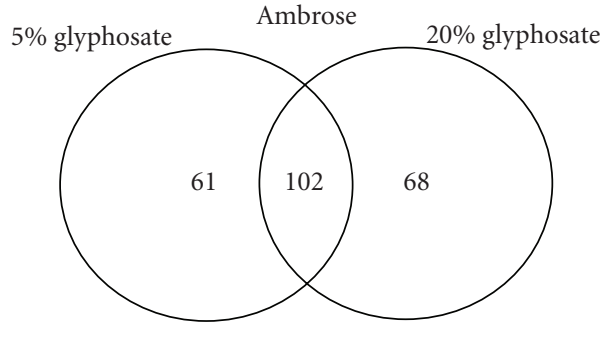

(a)

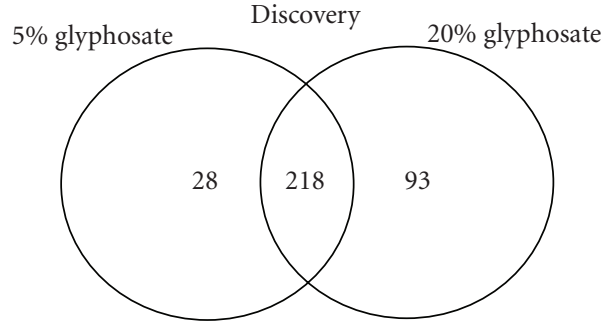

(b)

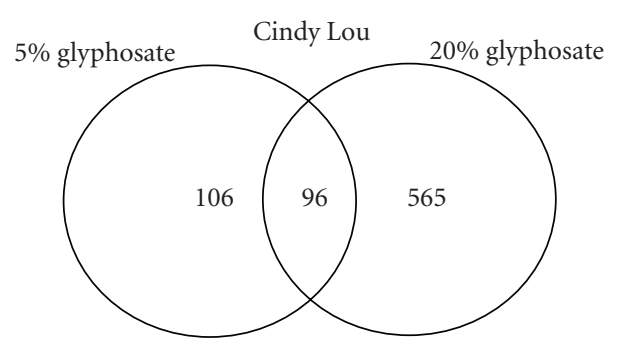

(c)

Figure 1: Venn diagrams representing the total number of differentially regulated probes in three Festuca genotypes in response to two glyphosate doses, 5\% and 20\%. (a) Ambrose; (b) Discovery; (c) Cindy Lou.

Thylakoid membrane phosphoprotein $14 \mathrm{kDa}$, chloroplast precursor forward: ACGAAGTTAGTGGCGAATGC, reverse: TTCCAGGTCTCATGGAGGTC. PCR amplification was performed with $18 \mathrm{~S}$ rRNA primers (forward: ATGATAACTCGACGGATCGC/reverse: CTTGGATGTGGTAGCCGTTT) and actin (GenBank accession AY663392, forward: GGATCTCACGGACTCCCTCAT/reverse: CGGCTGAGGTTGTGAAGGA) as control reaction.

2.5. Quantitative Real-Time RT-PCR ( $q R T-P C R$ ). Three micrograms of total RNA were used for first strand cDNA synthesis using the Superscript III reverse transcriptase (Invitrogen), quantified spectrophotometrically and diluted to $400 \mathrm{ng} \mu \mathrm{L}^{-1}$. One $\mu \mathrm{L}$ of this cDNA was amplified with $0.8 \mu \mathrm{M}$ of specific primers in a total of $20 \mu \mathrm{l}$ volume using SYBR green PCR master mix (Applied Biosystems) with Icycler Multicolor Real-time PCR Detection Systems (Bio-Rad Laboratories) [17, 18]. The quantification was performed using actin (GenBank accession AY663392, forward: GGATCTCACGGACTCCCTCAT/reverse: CGGCTGAGGTTGTGAAGGA) as an internal reference and three independent PCR results with acceptable efficiency (1.8-2.2) were averaged. Quantitative real-time RT-PCR analyses were performed for four probes selected for RT-PCR analysis.

\section{Results and Discussion}

3.1. Cross-Species Hybridization Analysis. Gene expression profiles of three Festuca species, Ambrose, Cindy Lou, and Discovery, were examined in response to increasing levels of glyphosate using the Affymetrix GeneChip Wheat Genome Array. This array contains 61,127 probe sets representing Triticum aestivum, T. turgidum, T. turgidum ssp. durum, T. monococcum, and Aegilops tauschii transcripts.
The CSH approach led to significant differential regulation of only 1337 probe sets (231 probes from Ambrose, 767 from Cindy Lou, and 339 probes from Discovery) at the defined threshold expression values of $P<.1$ and DE $<$ -2 or $\mathrm{DE}>2$. Although only $2.2 \%$ of the probes in total stayed above the threshold, biologically meaningful information could be extracted from this data set, which could be used to elucidate conserved mechanisms responsive to glyphosate common to fescues and wheat. The low percentage of hybridization might be explained by the presence of interspecies differences between the probe and target sequences. The single nucleotide polymorphisms may result in alteration of probe-hybridization affinities and hence, generate lower hybridization signal intensities [19]. Much higher hybridization ratios have been reported in recent studies exploiting CSH with cDNA arrays $[8,9]$ because cDNA platforms are likely more suitable for $\mathrm{CSH}$ studies owing to the longer cDNA probes. The wheat array platform chosen in our study appears to provide a benefit in that it enabled the detection and identification of highly conserved genes common to fescues and wheat, such as photosynthesis or reactive oxygen species scavenging.

3.2. Gene Expression Profiles in Festuca Species. The number of differentially expressed probes increased proportionally at $20 \%$ foliar glyphosate treatment. Hybridization with the Cindy Lou led to detection of a larger number of probes (Figure 1(c)), whereas Ambrose showed the lowest number of differentially expressed probes (Figure 1(a)). The total number of differentially expressed probe sets in Discovery was intermediate to that of Ambrose and Cindy Lou in response to glyphosate (Figure 1(b)). Interestingly, the number of probes with differential expression was almost constant in cultivar Ambrose irrespective of the glyphosate 


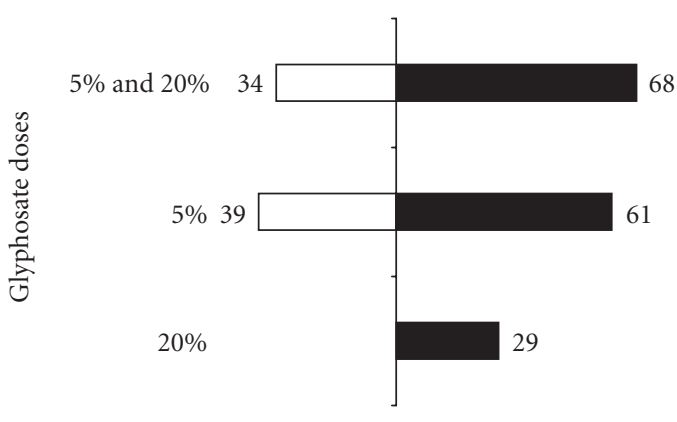

(a)

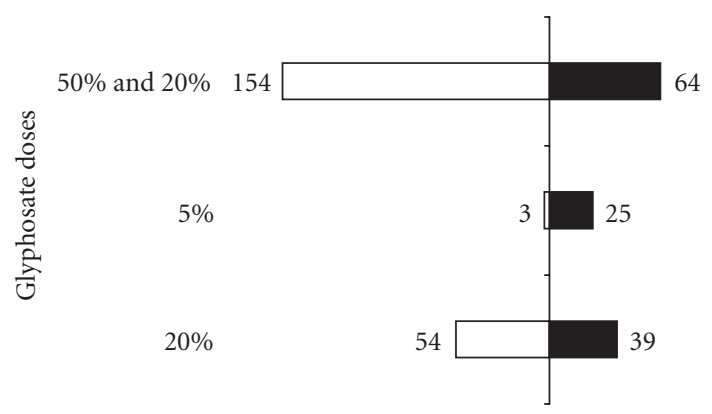

(b)

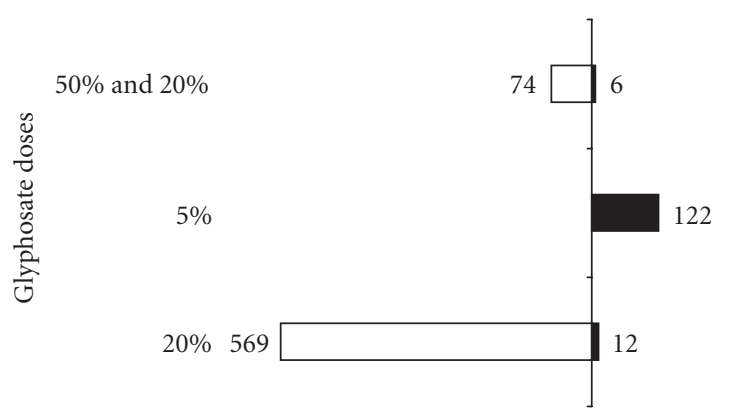

(c)

FIgURE 2: The total number of differentially regulated probe sets $(P<.1)$ in glyphosate applied plants. (a) Ambrose; (b) Discovery; (c) Cindy Lou. Up-regulated probes are represented by black bars, whereas down-regulated probes are represented by white bars.

application, whereas the number of probes increased with $20 \%$ glyphosate application for both Discovery and Cindy Lou with a strong response in the latter (Figure 1).

In Cindy Lou, most of the differentially expressed probes were found to be up-regulated at the $5 \%$ glyphosate application dose, but this pattern was opposite for the $20 \%$ glyphosate application (Figure 2(c)). Transcripts altered with $20 \%$ glyphosate applications were mostly down-regulated. In contrast, for Ambrose, the number of up-regulated probes was more than the down-regulated probes for both glyphosate doses (Figure 2(a)).

The total number of common up-regulated probes in Ambrose and Discovery at both glyphosate doses was greater than the number of common probes in Discovery and Cindy Lou (Figure 3). These results were opposite for downregulated probes. The mechanisms controlled by common down-regulated probe sets are likely more conserved among Cindy Lou and Discovery and appear to initiate a response to the higher doses of glyphosate.

3.3. Functional Analysis. Probes with differential expression were annotated by homology searches of target sequences using BLASTn in the TIGR wheat and rice genome databases (http://www.tigr.org/) and the GenBank $\mathrm{nr}$ database (http://www.ncbi.nlm.nih.gov/). Subsequently, we searched for functions using the ExPASy proteomics server [20] (Figure 4). Differentially expressed probes were grouped into 21 functional categories according to MIPS functional categories (http://www.mips.gsf.de/). The largest probe sets were categorized under "Photosynthesis" ( $25.3 \%$, average of three genotypes), "Metabolism" ( 24.6\%), "Protein Synthesis" ( 19.1\%), "Unclassified" ( $13.7 \%)$, "Transport \& Mechanisms" ( 10.1\%), "Energy" $(\sim 6.7 \%)$, and "Protein Fate" ( 6.4\%) (Figure 4). As could be expected, probes in the group "Photosynthesis" were down-regulated in all genotypes since one of the secondary responses of plants to glyphosate is the inhibition of photosynthesis via several routes [21-24]. In Ambrose, all differentially expressed probes except the ones in the photosynthesis category were found to be up-regulated at both glyphosate doses (Figure 5(a)), suggesting that most biological processes, except photosynthesis, were active in this genotype or showed enhanced expression. As for Cindy Lou, the transcript abundance pattern was found to be different from Ambrose. A major portion of the probes residing in the listed categories were up-regulated by the $5 \%$ glyphosate application. However, increasing glyphosate treatment to $20 \%$ resulted in down regulation of most probes (Figure 5(c)). These results support our proposal that glyphosate leads to the induction of a more profound downregulatory response when it is applied at a relatively higher dose $(20 \%)$ in Cindy Lou. This result was expected based on a previous report indicating that glyphosate led to the inhibition of many biological processes, including chlorophyll synthesis, plant tissue ion fluxes, and activity of antioxidative enzymes [25]. As for Discovery, most probes played roles in protein synthesis, photosynthesis, and transport mechanisms which were down-regulated (Figure 5(b)). Inhibition of protein synthesis was an expected response, because the major mode of action of glyphosate is inhibition of aromatic amino acid biosynthesis, and hence protein synthesis [26].

Cluster analysis using differentially expressed probes common to all genotypes for both glyphosate rates showed that differentially expressed probes in all Festuca genotypes in response to $5 \%$ (21 probes) and $20 \%$ glyphosate (71 probes) treatment grouped separately. The Treeview results indicated that differentially expressed probes of Cindy Lou and Discovery clustered together for both glyphosate rates (Figures 6(a) and 6(b)). Ambrose was shown to cluster separately from Cindy Lou and Discovery, which are proposed to be more tolerant to glyphosate in comparison to Ambrose [4]. In other words, transcriptome changes in Cindy Lou and Discovery at both glyphosate rates resembled each other. 


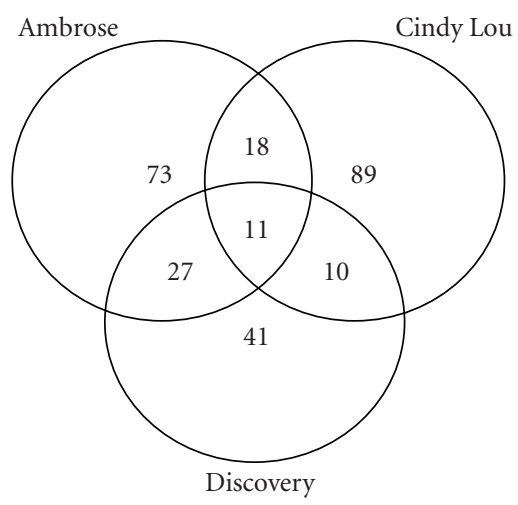

(a)

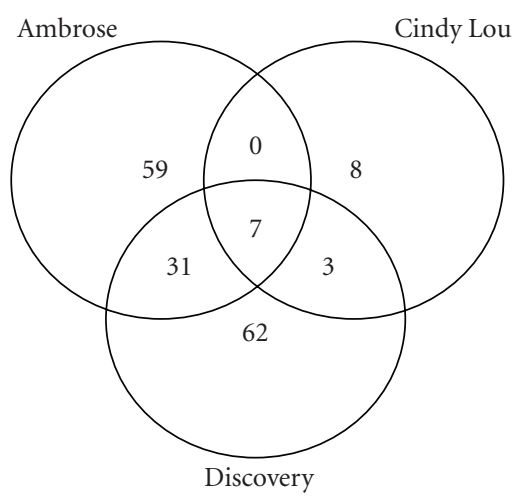

(c)

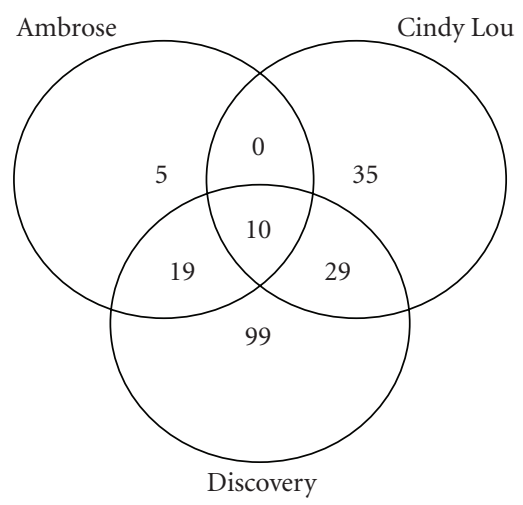

(b)

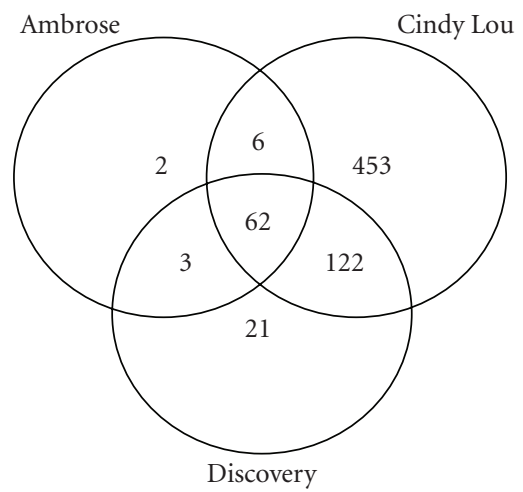

(d)

FIGURE 3: Venn diagrams representing the total number of differentially regulated probe sets common to three Festuca species. (a) Upregulated by $5 \%$ glyphosate application. (b) Down-regulated by $5 \%$ glyphosate application. (c) Up-regulated by $20 \%$ glyphosate application. (d) Down-regulated by $20 \%$ glyphosate application.

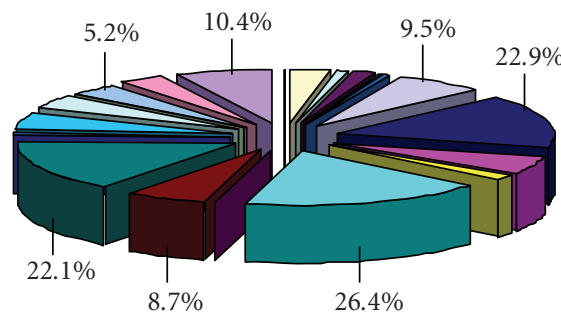

Biogenesis of cellular components

Cell cycle and DNA processing

$\square$ Cell defense and pathogenesis

$\square$ Cell fate

- Communication and signaling

- Cytoskeleton organization

$\square$ Development

$\square$ Energy

(a)

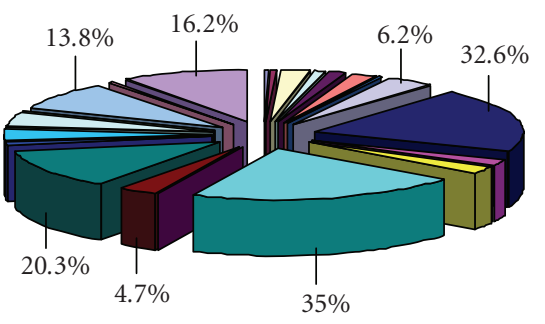

Metabolism

$\square$ No hit

$\square$ Other

$\square$ Photosynthesis

- Protein activity regulation

- Protein fate

$\square$ Protein synthesis

Protein with binding function

(b)

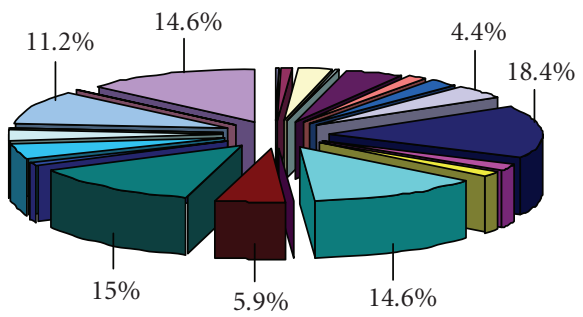

$\square$ Regulation and transcription

$\square$ Response to stimulus

$\square$ Storage protein

$\square$ Structural protein

$\square$ Transport and mechanisms

$\square$ Transposable elements etc.

$\square$ Unclassified

FIGURE 4: Representation of the functional annotation of all differentially regulated probes in Festuca species. (a) Ambrose, (b) Discovery, (c) Cindy Lou. 


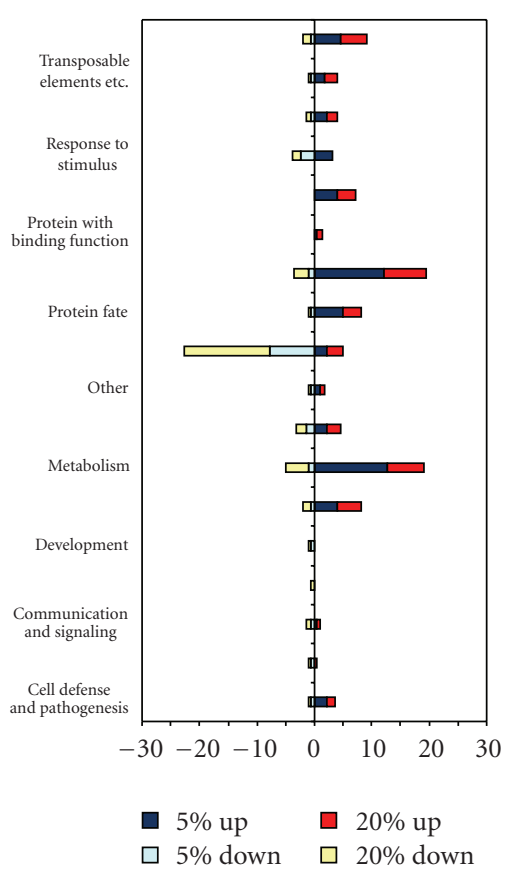

(a)

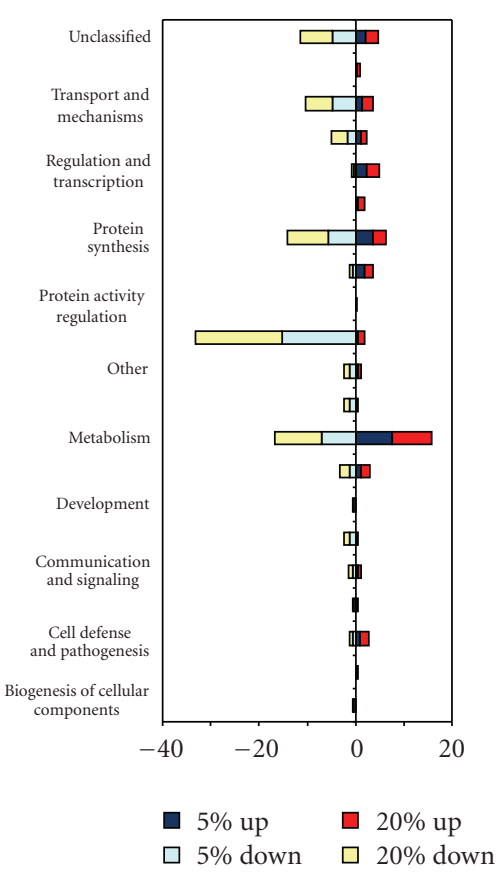

(b)

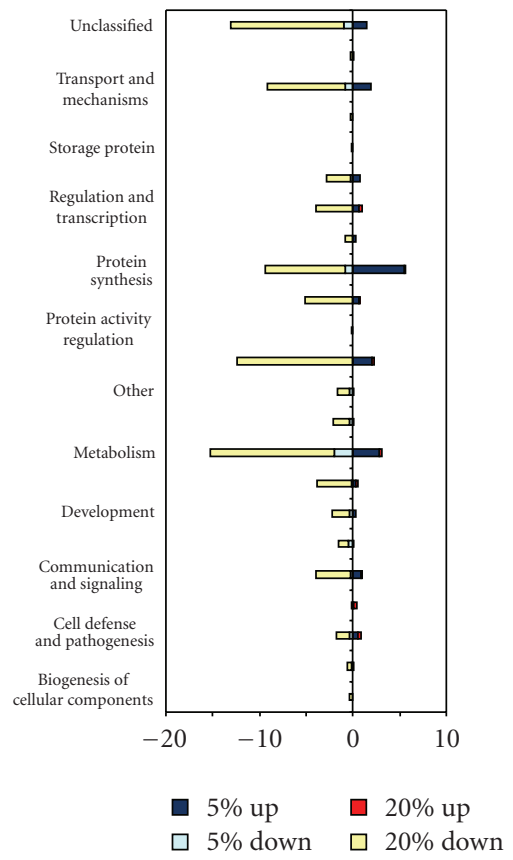

(c)

FiguRe 5: Functional categories of largest differentially regulated probe sets in three Festuca genotypes. (a) Ambrose, (b) Discovery, (c) Cindy Lou exposed to $5 \%$ and $20 \%$ glyphosate.

3.4. Reverse Transcriptase (RT) and Quantitative Real-Time ( $q R T$ ) PCR Analyses. RT-PCR was performed on both control and three 5\% glyphosate-treated Festuca to validate our CSH results. The candidate probe, TA.233.1.S1_AT, was found to have homology to "Alternative Oxidase" by functional analysis and was differentially expressed in all three genotypes. Sequencing of the amplified product in Fescue showed a high level of similarity wheat alternative oxidase genes (Triticum aestivum, $E$ value 1e-90). This probe was up-regulated at the $5 \%$ glyphosate treatment, in accordance with the CSH data (Figure 7). Amplification and functional analysis of "Thylakoid membrane phosphoprotein $14 \mathrm{kDa}$ ", "Germin-Like protein 1 precursor", and "Chlorophyll a/bbinding protein WCAB precursor" confirmed our CSH results. QRT-PCR performed on selected probes (Alternative oxidase, Germin-like protein 1 precursor, Chlorophyll a/bbinding protein WCAB precursor, chloroplast precursor) showed that microarray and qRT-PCR results were in good agreement $(r=93)$ with respect to trends of regulation.

3.5. Glyphosate Treatment Led to Down-Regulation of Photosynthesis Related Genes. Analysis of the differentially expressed probes with roles in photosynthesis revealed that glyphosate led to the down-regulation of most probes related to photosynthesis in all Festuca species at both glyphosate doses. This reduction in gene expression was mostly apparent in transcripts functioning in chlorophyll biosynthesis, photosystem activities, and RuBisCo, a key player in the Calvin cycle (Table 1). The decline in transcript abundance was more pronounced for plants treated with the higher glyphosate dose.
A major mode of action by glyphosate affects the aminolevulinic acid (ALA) pathway or the porphyrin biosynthesis pathway. In the ALA pathway, glyphosate interferes with the activity of aminolevulinate synthase preventing the conversion of succinyl CoA (from the tricarboxylic acid cycle) to ALA. Blockage of this step in porphyrin biosynthesis leads to a decline of compounds containing porphyrin, such as chlorophyll [27, 28]. Additionally, it has been reported that leaf chlorophyll content of plants exposed to sublethal doses of glyphosate is lower $[21,22]$. Hence, one of the primary reasons for the decline in expression levels of probes playing a role in photosynthesis might be related to the deleterious effect of glyphosate on chlorophyll. Glyphosate treatment was also shown to inhibit photosynthesis by blocking the allocation of carbon to starch [23], and resulted in an immediate and rapid decline in the level of ribulose bisphosphate and associated photosynthetic carbon metabolism in sugar beet [24]. These studies are consistent with the reduction in the levels of transcripts related to photosynthetic pathways being linked to the inhibitory effect of glyphosate in Festuca species.

3.6. Regulation of Detoxification of Reactive Oxygen Species (ROS) is Genotype Dependent. ROS generation causes oxidative damage to membrane lipids, DNA, and proteins [29]. CSH-based transcript profiling of Festuca species indicated that glyphosate treatment at different rates leads to the down-regulation of transcripts involved in the detoxification of ROS. The major strategy used by plants to tolerate oxidative stress is the production of anti-oxidative enzymes that convert ROS to less toxic compounds. In a previous 

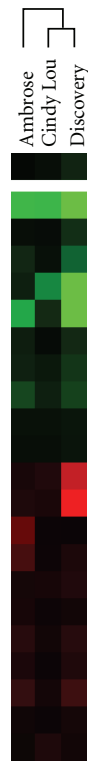

Germin-like protein 1 precurso

50 S ribosomal protein $\mathrm{L} 28$. chloroplast precursor Chlorophyll a/b-binding protein WCAB precursor Adenosine diphosphate glucose pyrophosphatase precursor Chlorophyll a/b-binding protein $\mathrm{WCAB}$ precursor Expansin-like protein A

Chlorophyll a/b-binding protein WCAB precursor Chlorophyll a/b-binding protein $\mathrm{WCAB}$ precursor

No hit

No hit

Thaumatin-like protein

Alternative oxidase

(O9M578) XIG

Translation initiation factor

Putative ER6 protein

Alcohol dehydrogenase

Translation initiation factor

Kelch repeat-containing F-box-like

Glucose-6-phosphate/phosphate translocator

Formate dehydrogenase. mitochondrial precursor

Sucrose: fructan 6-fructosyltransferase

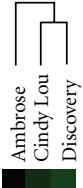

Precursor of CP29. core chlorophyll a/b binding (CAB) protein of photosystem II

Chlorophyll a/b-binding protein $\mathrm{CP} 29$ precursor

Chlorophyll A-B binding protein CP24 10A chloroplast precursor (CAB-10A) (LHCP)

Probable ubiquitin-fold modifier 1 precursor

Expansin-like protein A

Chloroplast 50S ribosomal protein L31-like

Putative glycolate oxidase (putative (S) -2-hydroxy-acid oxidase)

Photosystem I reaction centre subunit N, chloroplast precursor (PSI-N)

$50 \mathrm{~S}$ ribosomal protein $\mathrm{L} 15$

Glycine cleavage system $\mathrm{H}$ protein. mitochondrial precursor

Phosphoethanolamine methyltransferase

Putative chlorophyll a/b-binding protein type III

Thioredoxin M-type. chloroplast precursor (TRX-M)

Hypothetical protein OJ1001 B06.10

Putative chlorophyll a/b-binding protein type III

Chlorophyll a/b-binding protein precursor

Bundle sheath defective protein 2

Fructose-bisphosphate aldolase

Fructose-bisphosphate aldolase

9-cis-epoxycarotenoid dioxygenase 1

Thylakoid membrane phosphoprotein $14 \mathrm{kDa}$, chloroplast precursor

Acid phosphatase

Chlorophyll a/b-binding protein WCAB precursor

Chlorophyll a/b-binding protein CP29 precursor

Chlorophyll a/b-binding protein $\mathrm{CP} 29$ precursor
Photosystem I reaction center subunit psaK, chloroplast precursor (photosystem I subunit X)

Photosystem II subunit PsbS

Putative hydrolase

Chlorophyll a/b-binding protein precursor

Photosystem I reaction center subunit psaK, chloroplast precursor

Chlorophyll a/b-binding protein precursor

Ribulose-1, 5-bisphosphate carboxylase/oxygenase small subunit

Chloroplast 50S ribosomal protein $\mathrm{L} 23$

Oxygen-evolving enhancer protein 3-1 chloroplast precursor (OEE3)

Hypothetical protein OSJNBa0054F02.3

OSJNBa0053K19.11 protein

Rubisco large subunit

Rubisco large subunit

Senescence-associated protein

Chlorophyll a/b binding protein

Chlorophyll a/b-binding protein $\mathrm{WCAB}$ precursor

No hit

Chlorophyll a/b-binding protein WCAB precursor

Peroxiredoxin Q

Putative membrane protein $\mid$ Triticum aestivum $\mid$ NCBI_TaxID $=4565$

Putative plastid ribosomal protein $\mathrm{L} 34$

Actin

No hit

Chlorophyll a/b-binding protein WCAB precursor

Geranylgeranyl hydrogenase

Geranylgeranyl hydrogenase

Glutamyl-tRNA reductase 1. chloroplast precursor (GluTR)

Chlorophyll a/b-binding protein WCAB precursor

Chlorophyll a/b binding protein precursor

Photosystem I reaction center subunit XI, chloroplast precursor

Germin-like protein 1 precursor

RNA binding protein. putative

Thioredoxin peroxidase

Phosphoglycerate kinase. chloroplast precurso

Fructose 1, 6-bisphosphate aldolase

Photosystem I reaction center subunit psaK. chloroplast precursor

Photosystem II $10 \mathrm{kDa}$ polypeptide chloroplast precursor

50 S ribosomal protein $\mathrm{L} 28$. chloroplast precursor

Adenosine diphosphate glucose pyrophosphatase precursor

4-hydroxyphenylpyruvate dioxygenase (4HPPD) (HPD) (HPPDase)

Chloroplast rRNA-operon

Chloroplast rRNA-operon

Alternative oxidase

EFA27 for EF hand abscisic acid, $27 \mathrm{kD}$

Thaumatin-like protein

Pathogenesis-related protein 4

Chlorophyll a/b-binding protein WCAB precursor

PE-PGRS family protein

$<2>$

(b)

FigURE 6: Cluster analysis of probes with differential regulation in three Festuca genotypes. (a) 5\% glyphosate (b) $20 \%$ glyphosate. The color saturation reflects the fold change where green is for more than 2 fold down-regulated and red is for more than 2 fold up-regulated probes with $P<.1$. 
TABLE 1

(a) List of common or species-specific probes related to (a) photosynthesis, (b) oxidative stress, and (c) cell signaling and differentially expressed in response to two different doses of glyphosate. Given are the fold changes calculated by ANOVA. Up-regulation fold changes are given in bold letters, whereas downregulation by italics. No significant differential expression is shown with an empty cell. Ambrose probe fold changes are underlined, Discovery are doubleunderlined, and Cindy Lou are nonunderlined.

\begin{tabular}{|c|c|c|c|c|c|c|c|}
\hline & & \multicolumn{2}{|c|}{ Ambrose } & \multirow{2}{*}{\multicolumn{2}{|c|}{$\begin{array}{c}\text { Discovery } \\
\text { Fold Change }\end{array}$}} & \multicolumn{2}{|c|}{ Cindy Lou } \\
\hline & & & & & & & \\
\hline & & $\mathbf{5} \%$ & $20 \%$ & $5 \%$ & $20 \%$ & $\mathbf{5} \%$ & $20 \%$ \\
\hline Probe Set ID & Target Sequence & & & & & & \\
\hline Ta.27761.1.S1_x_at & $\begin{array}{l}\text { Photosystem I } \\
\text { reaction center } \\
\text { subunit psaK, } \\
\text { chloroplast precursor }\end{array}$ & $\underline{-3,30122}$ & $\underline{-13,2487}$ & $\underline{\underline{-3,01112}}$ & $\underline{\underline{-37,0513}}$ & - & $-6,62621$ \\
\hline Ta.27751.3.S1_x_at & $\begin{array}{l}\text { Photosystem I } \\
\text { reaction center } \\
\text { subunit XI, } \\
\text { chloroplast precursor }\end{array}$ & - & $\underline{-3,53086}$ & $\underline{\underline{-3,03125}}$ & $\underline{\underline{-6,11773}}$ & - & $-5,63676$ \\
\hline Ta.28750.1.S1_at & $\begin{array}{l}\text { Photosystem II } 10 \\
\text { kDa polypeptide } \\
\text { chloroplast precursor }\end{array}$ & - & $\underline{-2,6278}$ & $\underline{-4,16983}$ & $\underline{\underline{-17,2639}}$ & - & $-8,04824$ \\
\hline Ta.1161.1.S1_at & $\begin{array}{l}\text { Photosystem II } \\
\text { subunit PsbS }\end{array}$ & - & $\underline{-3,47497}$ & - & $\underline{\underline{-11,5118}}$ & - & $-3,58749$ \\
\hline Ta.1139.1.S1_at & $\begin{array}{l}\text { Precursor of CP29, } \\
\text { core chlorophyll a/b } \\
\text { binding (CAB) } \\
\text { protein of } \\
\text { photosystem II }\end{array}$ & $\underline{-5,04791}$ & $\underline{-28,6882}$ & $\underline{\underline{-7,37361}}$ & $\underline{\underline{-46,5839}}$ & - & $-18,6875$ \\
\hline Ta.28265.1.S1_at & $\begin{array}{l}\text { Oxygen-evolving } \\
\text { enhancer protein 3-1, } \\
\text { chloroplast precursor } \\
\text { (OEE3) }\end{array}$ & - & $\underline{-8,69806}$ & $\underline{\underline{-3,77085}}$ & $\underline{\underline{-5,07437}}$ & - & $-10,209$ \\
\hline Ta.30702.1.S1_x_at & $\begin{array}{l}\text { Chlorophyll } \\
\text { a/b-binding protein } \\
\text { WCAB precursor }\end{array}$ & $\underline{-40,9861}$ & $\underline{-58,6499}$ & $\underline{\underline{-64,5336}}$ & $\underline{\underline{-98,1407}}$ & $-10,1345$ & $-119,736$ \\
\hline Ta.20639.3.S1_x_at & $\begin{array}{l}\text { Chlorophyll } \\
\text { a/b-binding protein } \\
\text { precursor }\end{array}$ & $\underline{-3,23933}$ & $\underline{-6,25985}$ & $\underline{\underline{-6,19484}}$ & $\underline{\underline{-18,7793}}$ & - & $-2,68378$ \\
\hline TaAffx.128414.219.S1_x_at & Rubisco large subunit & $-9,75494$ & $\underline{-16,4849}$ & $\underline{\underline{-3,08632}}$ & $\underline{\underline{-10,8861}}$ & - & $-37,5039$ \\
\hline Ta.2752.2.S1_x_at & $\begin{array}{l}\text { Ribulose-1,5- } \\
\text { bisphosphate } \\
\text { carboxy- } \\
\text { lase/oxygenase small } \\
\text { subunit }\end{array}$ & - & $\underline{-14,2542}$ & - & $\underline{\underline{-27,3256}}$ & - & $-7,39744$ \\
\hline
\end{tabular}

(b)

\begin{tabular}{|c|c|c|c|c|c|}
\hline \multirow[b]{3}{*}{ Probe Set ID } & \multirow[b]{3}{*}{ Target Sequence } & \multicolumn{2}{|c|}{ Cindy Lou } & \multicolumn{2}{|c|}{ Discovery } \\
\hline & & \multicolumn{4}{|c|}{ Fold Change } \\
\hline & & $5 \%$ & $20 \%$ & $5 \%$ & $20 \%$ \\
\hline Ta.28714.1.S1_at & Thioredoxin peroxidase & - & $-10,1624$ & $-2,57569$ & $-17,9772$ \\
\hline Ta.6572.1.S1_a_at & Peroxiredoxin Q & - & $-17,3425$ & $-4,85985$ & $\underline{-7,80475}$ \\
\hline Ta.18063.2.S1_at & Putative glutathione peroxidase & $-2,69247$ & $-5,38618$ & - & - \\
\hline Ta.547.1.S1_at & Cytosolic glutathione reductase & - & - & 9,12843 & 11,6039 \\
\hline Ta.14644.2.S1_x_at & Superoxide dismutase $[\mathrm{Cu}-\mathrm{Zn}] 4 \mathrm{~A}$ & - & - & 2,52839 & 2,62177 \\
\hline
\end{tabular}


(c)

\begin{tabular}{|c|c|c|c|c|c|}
\hline \multirow[b]{3}{*}{ Probe Set ID } & \multirow[b]{3}{*}{ Target Sequence } & \multicolumn{2}{|c|}{ Cindy Lou } & \multicolumn{2}{|c|}{ Discovery } \\
\hline & & \multicolumn{4}{|c|}{ Fold Change } \\
\hline & & $5 \%$ & $20 \%$ & $5 \%$ & $20 \%$ \\
\hline Ta.6269.1.S1_at & Putative serine/threonine kinase 38 & - & $-3,59976$ & & - \\
\hline Ta.991.1.S1_a_at & Serine/threonine-protein kinase SAPK8 & - & $-7,70463$ & - & - \\
\hline TaAffx.86456.1.S1_s_at & Putative calcium/calmodulin-dependent protein kinase CaMK & - & $-6,76413$ & - & - \\
\hline Ta.11837.1.S1_at & Calmodulin & - & $-5,03177$ & - & - \\
\hline Ta.6979.1.S1_s_at & Phosphatidylinositol 3-and 4-kinase family-like, & - & $-40,9189$ & - & - \\
\hline Ta.1890.1.S1_x_at & Nt-iaa28 deduced protein & $-2,85957$ & $-2,85957$ & - & - \\
\hline Ta.6968.2.S1_a_at & Ethylene-responsive small GTP-binding protein & - & $-2,60726$ & - & - \\
\hline Ta.25390.1.S1_s_at & (Q91W51) WASP family 1 & - & - & $\underline{3,49126}$ & $\underline{4,82506}$ \\
\hline
\end{tabular}

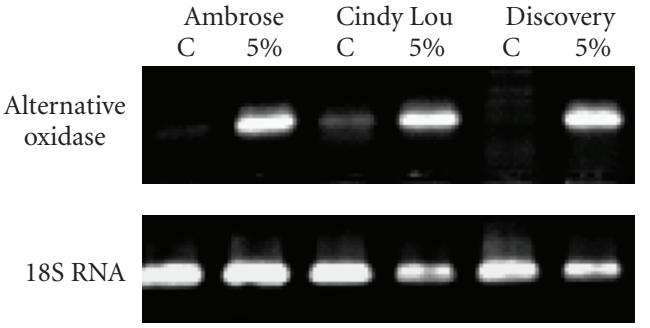

FIGURE 7: A representative picture of validation of microarray result using RT PCR for one common Festuca probe set.

study, it has been shown that glyphosate will exert its deleterious effects on maize plants by amplifying lipid peroxidation of biomembranes (MDA) [25]. Additionally, it was postulated that the appearance of a small number of changes in lipid peroxidation and antioxidative defense mechanisms in susceptible and resistant soybean cultivars exposed to sublethal doses of glyphosate [30] In this study, probes with homology to antioxidative enzymes, such as putative glutathione peroxidase, thioredoxin peroxidase, and peroxiredoxin $\mathrm{Q}$ were down-regulated. The major reason for down-regulation of these peroxidases might be the inhibition of ALA by glyphosate action.

This is the first report to analyze the potential of crossspecies hybridization in Fescue species and the data and analyses will help extend our knowledge on the cellular processes affected by glyphosate. This study is important for paving the way to better understand the mechanisms and pathways regulating glyphosate responses of Festuca species.

\section{Acknowledgments}

This study was funded by EC-Marie Curie IRG grant. The authors acknowledge Drs. H Bohnert, L Rossini, and W Schmitt for critical reading the manuscript and helpful discussion during the data analysis.

\section{References}

[1] H. C. Steinrücken and N. Amrhein, "The herbicide glyphosate is a potent inhibitor of 5-enolpyruvyl-shikimic acid-3phosphate synthase," Biochemical and Biophysical Research Communications, vol. 94, no. 4, pp. 1207-1212, 1980.

[2] S. E. Hart, J. F. Derr, D. W. Lycan, C. Rose-Fricker, and W. A. Meyer, "Increased glyphosate tolerance in 'Aurora Gold' hard fescue (Festuca longifolia)," Weed Technology, vol. 19, no. 3, pp. 640-646, 2005.

[3] A. D. Baylis, "Why glyphosate is a global herbicide: strengths, weaknesses and prospects," Pest Management Science, vol. 56, no. 4, pp. 299-308, 2000.

[4] Y. S. Su, L. Ozturk, I. Cakmak, and H. Budak, "Turfgrass species response exposed to increasing rates of glyphosate application," European Journal of Agronomy, vol. 31, no. 3, pp. 120-125, 2009.

[5] S. A. McCarroll, C. T. Murphy, S. Zou, et al., "Comparing genomic expression patterns across species identifies shared transcriptional profile in aging," Nature Genetics, vol. 36, no. 2, pp. 197-204, 2004.

[6] T. R. Hughes, M. J. Marton, A. R. Jones, et al., "Functional discovery via a compendium of expression profiles," Cell, vol. 102, no. 1, pp. 109-126, 2000.

[7] J. Ihmels, S. Bergmann, J. Berman, and N. Barkai, "Comparative gene expression analysis by differential clustering approach: application to the Candida albicans transcription program," PLoS Genetics, vol. 1, no. 3, article e39, 2005.

[8] Y. Sun, H. Li, Y. Liu, et al., "Cross-species transcriptional profiles establish a functional portrait of embryonic stem cells," Genomics, vol. 89, no. 1, pp. 22-35, 2007.

[9] M. Vallée, C. Robert, S. Méthot, M.-F. Palin, and M.A. Sirard, "Cross-species hybridizations on a multi-species cDNA microarray to identify evolutionarily conserved genes expressed in oocytes," BMC Genomics, vol. 7, article 113, 2006.

[10] C. Bar-Or, M. Bar-Eyal, T. Z. Gal, Y. Kapulnik, H. Czosnek, and H. Koltai, "Derivation of species-specific hybridization-like knowledge out of cross-species hybridization results," $B M C$ Genomics, vol. 7, article 110, 2006.

[11] E. S. Jones, N. L. Mahoney, M. D. Hayward, et al., "An enhanced molecular marker based genetic map of perennial ryegrass (Lolium perenne L.) reveals comparative relationships with other Poaceae genomes," Genome, vol. 45, no. 2, pp. 282295, 2002. 
[12] R. J. Soreng and J. I. Davis, "Phylogenetics and character evolution in the grass family (Poaceae): simultaneous analysis of morphological and chloroplast DNA restriction site character sets," Botanical Review, vol. 64, no. 1, pp. 1-85, 1998.

[13] N. Z. Ergen, J. Thimmapuram, H. J. Bohnert, and H. Budak, "Transcriptome pathways unique to dehydration tolerant relatives of modern wheat," Functional and Integrative Genomics, vol. 9, no. 3, pp. 377-396, 2009.

[14] M. B. Eisen, P. T. Spellman, P. O. Brown, and D. Botstein, "Cluster analysis and display of genome-wide expression patterns," Proceedings of the National Academy of Sciences of the United States of America, vol. 95, no. 25, pp. 14863-14868, 1998.

[15] R. D. M. Page, "TREEVIEW: An application to display phylogenetic trees on personal computers," Computational and Applied Biosciences, vol. 12, pp. 357-358, 1996.

[16] O. Cebeci, B. Kokturk, N. Ergen, L. Ozturk, I. Cakmak, and H. Budak, "Differential expression of wheat transcriptomes in response to varying cadmium concentrations," Biologia Plantarum, vol. 52, no. 4, pp. 703-708, 2008.

[17] N. Z. Ergen and H. Budak, "Sequencing over 13000 expressed sequence tags from six subtractive cDNA libraries of wild and modern wheats following slow drought stress," Plant, Cell \& Environment, vol. 32, no. 3, pp. 220-236, 2009.

[18] N. Z. Ergen, G. Dinler, R. C. Shearman, and H. Budak, "Identifying, cloning and structural analysis of differentially expressed genes upon Puccinia infection of Festuca rubra var. rubra," Gene, vol. 393, no. 1-2, pp. 145-152, 2007.

[19] D. Benovoy, T. Kwan, and J. Majewski, "Effect of polymorphisms within probe-target sequences on olignonucleotide microarray experiments," Nucleic Acids Research, vol. 36, no. 13, pp. 4417-4423, 2008.

[20] E. Gasteiger, A. Gattiker, C. Hoogland, I. Ivanyi, R. D. Appel, and A. Bairoch, "ExPASy: the proteomics server for in-depth protein knowledge and analysis," Nucleic Acids Research, vol. 31, no. 13, pp. 3784-3788, 2003.

[21] P. K. Wong, "Effects of 2,4-D, glyphosate and paraquat on growth, photosynthesis and chlorophyll-a synthesis of Scenedesmus quadricauda Berb 614," Chemosphere, vol. 41, no. 1-2, pp. 177-182, 2000.

[22] S. Tan, R. Evans, and B. Singh, "Herbicidal inhibitors of amino acid biosynthesis and herbicide-tolerant crops," Amino Acids, vol. 30, no. 2, pp. 195-204, 2006.

[23] D. R. Geiger, S. W. Kapitan, and M. A. Tucci, "Glyphosate inhibits photosynthesis and allocation of carbon to to starch in sugar beet leaves," Plant Physiology, vol. 82, pp. 468-472, 1986.

[24] J. C. Servaites, M. A. Tucci, and D. R. Geiger, "Glyphosate effects on carbon assimilation, Ribulose Bisphosphate Carboxylase activity, and metabolite levels in sugar beet leaves," Plant Physiology, vol. 85, pp. 370-374, 1987.

[25] I. G. Sergiev, V. S. Alexieva, S. V. Ivanov, I. I. Moskova, and E. N. Karanov, "The phenylurea cytokinin 4PU-30 protects maize plants against glyphosate action," Pesticide Biochemistry and Physiology, vol. 85, no. 3, pp. 139-146, 2006.

[26] N. Amrhein, B. Deus, P. Gehrke, and P. Steinrücken, "The site of the inhibition of the shikimate pathway by glyphosate," Plant Physiology, vol. 66, pp. 830-834, 1980.

[27] L. M. Kitchen, W. W. Witt, and C. E. Rieck, "Inhibition of delta-aminolevulinic acid synthesis by glyphosate," Weed Science, vol. 29, pp. 571-577, 1981.
[28] A. Zaidi, M. S. Khan, and P. Q. Rizvi, "Effect of herbicides on growth, nodulation and nitrogen content of greengram," Agronomy for Sustainable Development, vol. 25, no. 4, pp. 497504, 2005.

[29] K. Apel and H. Hirt, "Reactive oxygen species: metabolism, oxidative stress, and signal transduction," Annual Review of Plant Biology, vol. 55, pp. 373-399, 2004.

[30] C. A. Moldes, L. O. Medici, O. S. Abraha, S. M. Tsai, and R. A. Azevedo, "Biochemical responses of glyphosate resistant and susceptible soybean plants exposed to glyphosate," Acta Physiologiae Plantarum, vol. 30, pp. 469-479, 2008. 

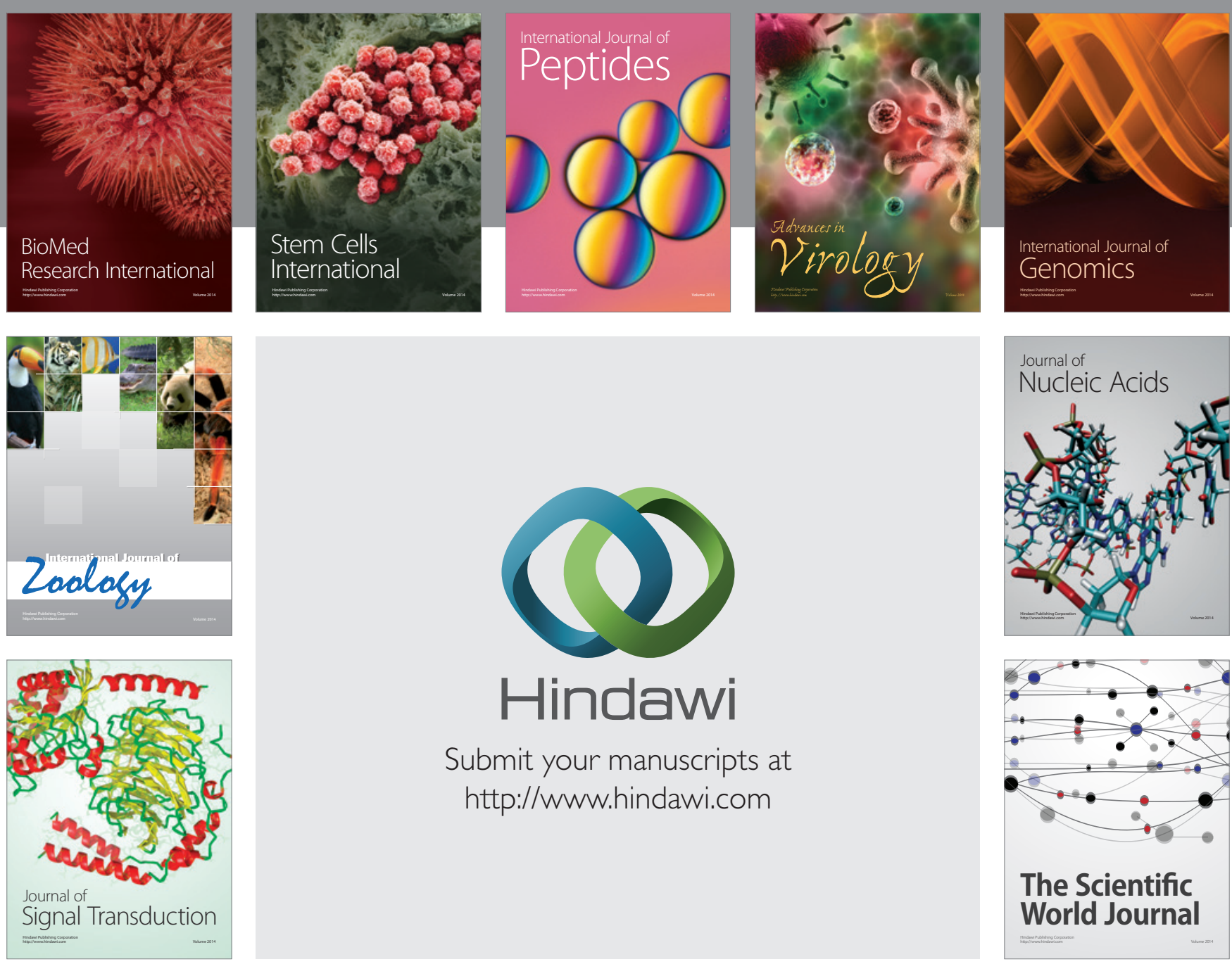

Submit your manuscripts at

http://www.hindawi.com
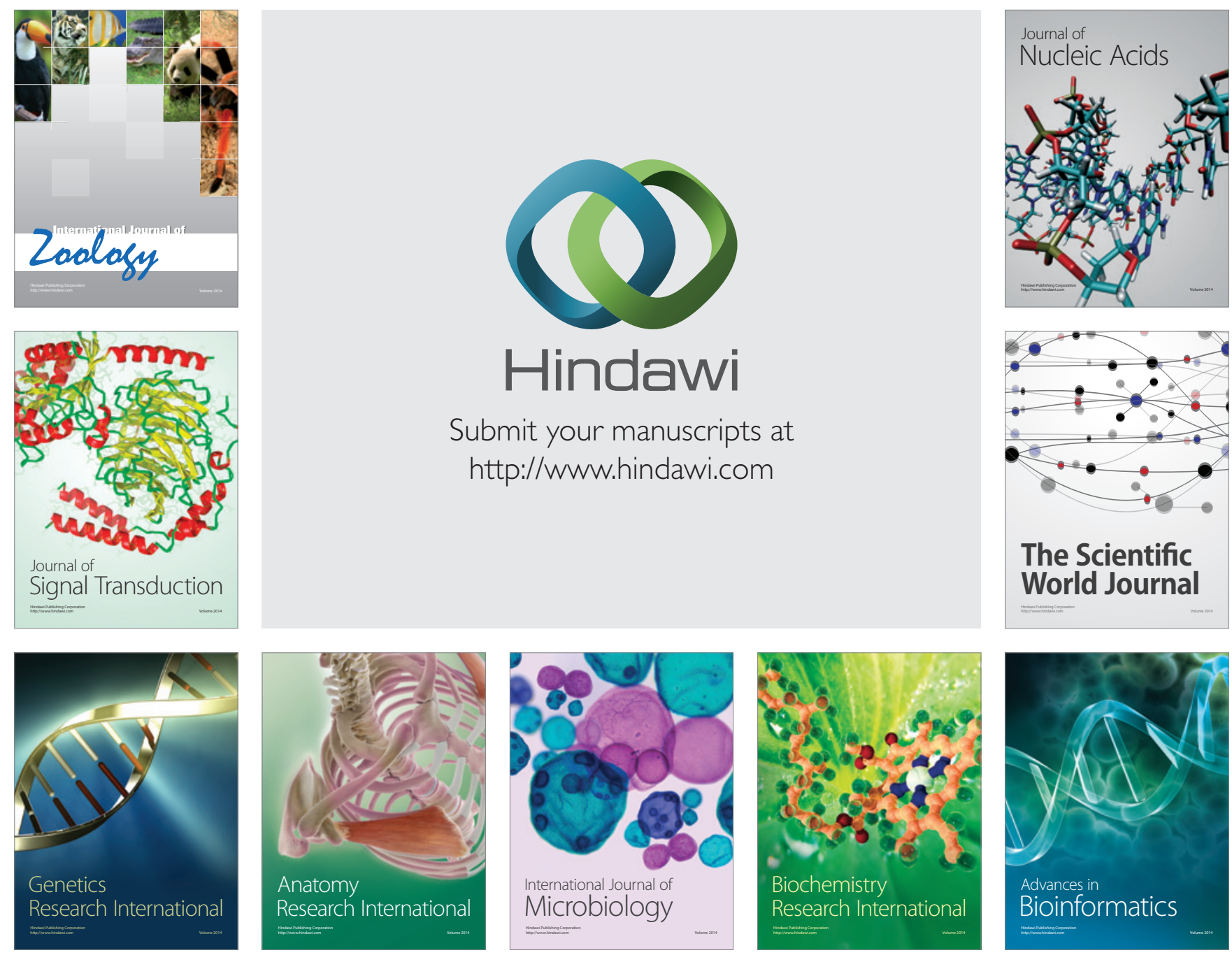

The Scientific World Journal
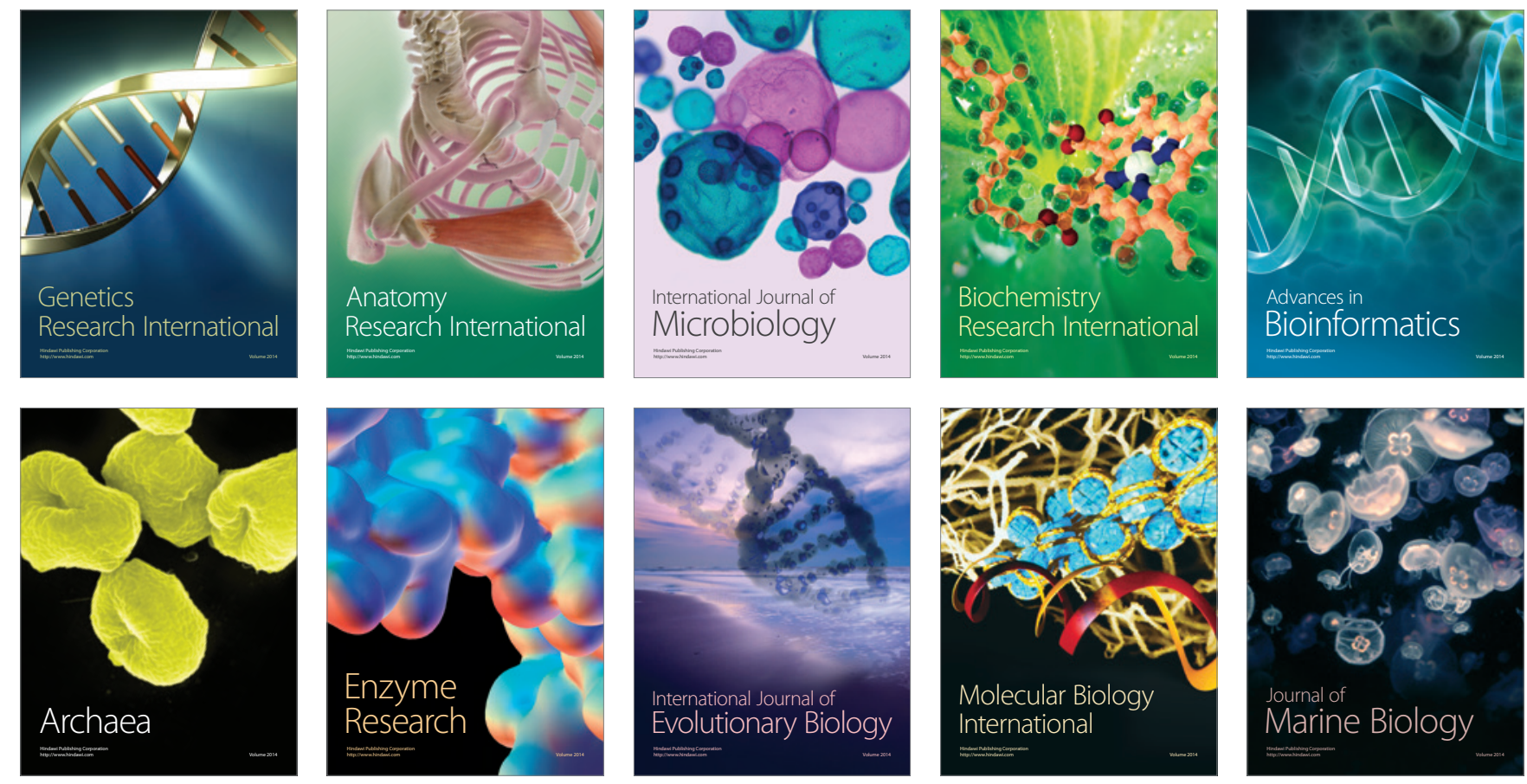